\title{
Pedagogical Practice as Way to Find out Pedagogical Barriers
}

\author{
Dorofeeva M. ${ }^{1}$, Timoshenko A. I. ${ }^{2}$, Tretyakova L. R. ${ }^{3} \&$ Rogaleva E. V. ${ }^{3}$ \\ ${ }^{1}$ PostgraduateIrkutsk State University, Irkutsk, Russian Federation \\ ${ }^{2}$ Doctor of Education, Professor Irkutsk State University, Irkutsk, Russian Federation \\ ${ }^{3}$ Candidate of Pedagogic Sciences, DocentIrkutsk State University, Irkutsk, Russian Federation \\ Correspondence: Dorofeeva M. S, PostgraduateIrkutsk State University, Irkutsk, Russian Federation
}

Received: November 5, 2019

Accepted: December 21, 2019

Online Published: December 27, 2019

doi:10.5430/ijhe.v9n1p199

URL: https://doi.org/10.5430/ijhe.v9n1p199

\begin{abstract}
There is a problem of finding out the cognitive barriers during the pedagogical practice (teaching practice) among students of training college in the article. We made an analysis of the definition "pedagogical barriers" among Russian and foreign researchers. The author's definition of this notion is given. The importance of early finding out pedagogical barriers and working out the ways of preventive measures are presented. The methods and approaches used during the experiment are described. The results of the research on finding out pedagogical barriers are given.
\end{abstract}

Keywords: pedagogical practice (training), pedagogical barriers, situations, difficulties, students-trainees

\section{Introduction}

The professional training of a future teacher in the system of secondary vocational education is realized in the process of studying at the college. It includes theoretical and practical education.

A high level of professional orientation is a result of a teacher's qualification in secondary vocational education. This orientation is more effective during pedagogical training.

The purpose of training is in the preparation for basic forms of professional occupation, realization of acquired professional knowledge, skills, abilities and professional adaptation. It is also going into profession, acquiring social role and professional self-determination, forming positions and integration of personal and professional characteristics.

In this connection researches have a special place at mastering educational process on this level. Problems revealing the role of practice during professional forming of a future teacher in professional and personal development are the subject of analysis of these researches.

Students use got theoretical knowledge during pedagogical practice. They develop professional skills that lead to self-realization, self-expression, self-determination of personality from professional activity and competency building approach.

\section{Materials and Methods}

The reasons of pedagogical barriers among students-trainees and ways to overcome them have been determined based on the analysis of pedagogical reports by a questioning method.

Students having pedagogical practice from the second, third and fourth years by specialty "Teaching at primary schools" took part in the analysis. The total number was one hundred people.

The problems concerning different aspects (reasons) of appearance the pedagogical barriers were reflected on reports and questionnaires. Students described their feelings and difficulties that appeared in the process of pedagogical practice. Later on they could understand them and correct their professional activity with their mentor (teacher) (Rogov E.I., (1999)

In that way the analysis of presented results allowed to make the following conclusions. Summarizing definitions the respondents (students) gave to pedagogical barriers, we can formulate the following:

Pedagogical barriers are a complex of some difficulties facing with which a teacher can't quickly make a right decision about the way how to overcome them. 
Students-trainees indicated that during such difficulties they felt embarrassed, diffident, they did not know what to do and how to solve emerged difficulties or what way of solution would be the most effective in that situation.

\section{Literature Review}

The development of professional competences of college students during pedagogical practice is being an actual topic during the last decade that attracts attention of both Russian (Kuznetsov V.V., 2019) and foreign (Voronov V.K., 2013; Obradovich MSc Bosho., 2013; Dancy M \& Henderson C., 2010; Henderson C \& Dancy MH., 2007; Forzani FM., 2014) scientists (Sepehri \& Sheikhalizadeh, 2019).

A.B. Efanov notes that "Pedagogical practice is a kind of academic studies in the process of which students by themselves in a certain educational institution fulfill real tasks of education, upbringing and development of pupils determined by educational program of pedagogical practice" (Efanov A.V. \& Gadelyiina O.I., 2011).

In interpretation by L.S. Vygodskii teaching and development are not identified but at the same time the leading role of teaching is underlined. It creates a zone of the closest development for a learner that leads to working out means and ways of orientation in reality (Vygotskii L.S., 2019).

From the point of view of K.D. Ushinskii methods of teaching can be learned from s book and from words of a teacher but one can get a skill in using this method only by a long and lasting a long time practice (Ushinskii K.D., 1959).

Yu. K. Babanskii noted that understanding of mechanisms and principals of teaching and upbringing took place in the process of pedagogical practice. Students get professional skills, abilities and experience of practical activity (Babanskii Yu.K., 1985).

In a complex of professional modules the practical activity of students helps find directions and perspectives of professional growth in future. It helps strengthen adequate professional self-appraisal and form professional identification of a future teacher (Pavlova Ya.V. \& Sakovich S.I., 2017).

Pedagogical practice is a kind of educational work that aims at theoretical and practical knowledge received by students in the process of education. Pedagogical practice is an acquisition and perfection of practical skills and abilities in the chosen specialty and school preparation.

The pedagogical practice of students is the main part of the training program for mid-level specialists (teachers) from a pedagogical college. Pedagogical practices can be either a continuous cycle or an alternation of theoretical lessons by days (weeks) if there is a connection between contents of the practice and theoretical education.

By analyzing the essence of the concept of pedagogical practice we examined pedagogical difficulties that appeared during it within the framework of a separate institution.

The issues of pedagogical difficulties (barriers) were studied by Yu.K. Babanskii, N.V. Kuzmina, B.T. Likhacheva, A.K. Makarova, V.A. Slastenin (Kuzmina N.V., 1990).

The mentioned authors viewed pedagogical practice as a process of solving pedagogical tasks. N.V. Kuzmina interprets professional pedagogical difficulties as a subjective tension state, heaviness, dissatisfaction that are caused by external factors of practice and depending on these factors, character of readiness to the practice and attitude to it (Kuzmina N.V., 2001).

T.S. Polyakova thinks that difficulties (barriers) are an expression of contradiction between a necessity to carry out a certain activity and lack of knowledge and skills that provide its realization. That's why one of considerable problems in the theory and practice of good organization of work is a problem of difficulties in a person's activity, an elaboration of ways to notice and overcome them (Polyakova T.S., 1983).

Some authors point out that the function of professional and pedagogical difficulties can be carried out if a teacher has a professional idea "I am a conception" and if a teacher has a pedagogical reflection.

There are three types of professional and pedagogical barriers in the scientific and psycho-educational literature:

- motivational barriers;

- communicative barriers;

- cognitive barriers.

Each of these types consists of similar components of barriers: value and notional, informative, operational, emotional and volitional, controlling and reflexive. 


\section{Results}

There were defined situations during the conducted experiment. Pedagogical barriers were evinced among students who had pedagogical practice:

1. Indiscipline among pupils (conflicts between them, walking in a lecture-room, noise during a lesson, using slang and obscene language in the presence of a teacher at a lesson).

These situations form pedagogical barriers. They are connected with pedagogical work that is carried on by teachers at school and it is considered to be the most difficult from students' point of view. The complication of these difficulties is connected with the fact that students-trainees build up friendship and fellowship with pupils. They do not try to build up communication with pupils from the position of a teacher. In its turn it is reflected on an image of a teacher pupils have looking at a student-trainee. It leads to more difficulties.

2. Evaluating pupils at a lesson, marking them.

During pedagogical practice students-trainees for the first time face the difficulties of evaluating knowledge pupils show them. Most of students understand that by evaluating pupils they also evaluate themselves. For example, they evaluate how he (she) has managed to inform a pupil with necessary information and to give him a motivation to study. There is a choice to put a mark a pupil deserves or to be indulgent. Facing such barriers students-trainees ask for a help pedagogical methodologists and teachers who are in charge of them. They adopt a system which has been approved by them during work.

3. Difficulties in relations between teacher and pupil, teacher and teacher, conflicts between students-trainees and leading methodologists of pedagogical practices, rejection students as teachers by pupils.

Discussing the first type of difficulties, such barriers appear during pedagogical practice. Students-trainees are not taken seriously by pupils as they are younger than their teachers and they are attractive to pupils. Teachers also do not regard students who have pedagogical practice in their classes seriously.

Such a situation arises because of unwillingness to cooperate both from teachers' side and from students'. However, we can note that students learn to build up a businesslike dialogue with their colleagues during pedagogical practice. They also adopt experience of methodologists and begin to use professional competences teachers share with them.

4. Complexity when giving material, planning lessons, inability to explain an importance of a subject under study.

This type of barriers appears so often among students and has a cognitive nature. Appealing to teachers and methodologists who are in charge of pedagogical practice is a way to resolve these barriers.

At the same time we can note that this type of barriers is realized by students-trainees least of all because a way to resolve it seems to be the easiest. We should note that these barriers refer to difficulties of diagnostic, organizational and methodical, communicative, stimulating, regulating, controlling and evaluating and performing components. Mostly these types of pedagogical barriers consist of several blocks.

However, pedagogical barriers do not have a single solution as students mark. Consequently, choosing a variant to resolve difficulties students should take into account individual and personal peculiarities of pupils, in case, if a barrier is in interaction with one pupil and peculiarities of a class.

There are three reasons of pedagogical barriers that we can meet quite often:

Individual and personal - most often students-trainees included individual and personal peculiarities of pupils, their unwillingness to study and to learn a subject in the block. They also added children of an awkward age there.

Poor informational pedagogical experience, lack of sufficient volume of theoretical knowledge about a subject.

Organizational and active - unplanned actions, lack of skill to organize a lesson in a right way, inability to time a lesson, sophisticated language of a book (Zhirkova Z.S., 2012).

The main barrier is still a difficulty connected with a shift of theoretical knowledge to the field of solving pedagogical problems.

Theoretical knowledge received by students at lectures and seminars will be used practically at school.

In reality it is not like this because the usage of theoretical knowledge in practice is not immediate. All basic types of activities directed at forming abilities to use theoretical knowledge when solving practical tasks should be taken into account during education. 
According to Slastetin V.A. the whole process of professional development of a future teacher should model a structure of pedagogical activity, if possible (Slastenin V.A., 2018)

Thus in order to make the process of teaching practical and oriented in pedagogical educational institution and to compare received knowledge with real school problems students-trainees should perceive theoretical knowledge though prism of practical issues.

\section{Discussions}

Applying theoretical knowledge in pedagogy, psychology, methodology and having good knowledge, students experience serious difficulties using them in practice during teaching. Unfortunately, a look on teacher's work and school's work "from the inside" can bring certain corrections about the original image of a teacher as a profession (Mkrtchyan N.M., 2016).

There was a question in the research: how satisfaction and dissatisfaction of pedagogical practice influence on overcoming the pedagogical barriers and help form positive attitude to pedagogical work.

The following results were received:

an image of a teacher as a profession was changed for the better during pedagogical practice (56\%);

an image of a teacher as a profession was changed for the worse during pedagogical practice (13\%);

changes in opinions were not occurred (34\%);

an analysis of survey's results also has allowed to single out factors determining that pedagogical barriers among students depend on satisfaction of pedagogical practice;

satisfied by pedagogical practice students would again choose a teacher profession (60\%);

non-satisfied by pedagogical practice students would not choose a teacher profession (14\%).

We can suppose that analyzing this research students-trainee will manage to cope with barriers successfully during pedagogical practice if they follow the next conditions:

purposeful study of psychological and pedagogical disciplines for having successful pedagogical practice;

applying methods directed at finding out difficulties and ways of reaction on them among students before practice and for diagnostics and prevention possible barriers;

creating situations of success among students-trainees during pedagogical practice;

taking part in different kinds of lessons that are directed at understanding of arising difficulties and ways to solve them constructively.

\section{Conclusion}

Analyzing the results of received research we made the following conclusions. Facing with pedagogical difficulties students-trainees incline to use coincident behavior for protection or a mechanism of psychological protection or overcoming arising barriers.

This tendency of researches is interesting to us as received results of the experiment can help increase the level of professional competence of future teachers.

\section{References}

Babanskii Yu.K. (1985). Methods of teaching in a present-day comprehensive school: Scientific Eds. Moscow. Enlightenment Publ, 208.

Dancy M \& Henderson C. (2010). Pedagogical practices and instructional change of physics faculty. American Journal of Physics, 78(10), 1056.

Efanov A.V. \& Gadelyiina O.I. (2011). Pedagogical practice: the basics of organization and methodology of behavior. Methods handbook. Yekaterinburg, Russian State Professional and Pedagogical University Publ, 69.

Forzani FM. (2014). Understanding "Core practices" and "practice-based" teacher education: Learning from the past. Journal of Teacher Education, 65(4), 357-368.

Henderson C \& Dancy MH. (2007). Barriers to the use of research-based instructional strategies: The influence of both individual and situational characteristics. Physical Review Special Topics - Physics Education Research, $3(2), 1-14$. 
Kuzmina N.V. (1990). Professionalism of teacher's personality and training manager. Moscow.

Kuzmina N.V. (2001). Acmeological theory of increasing the quality of teachers' preparation. Moscow.

Kuznetsov V.V. (2019). Introduction to pedagogical activity; book and educational aid for secondary vocational education. 3rd ed. Rev. ed. Moscow, Yurite Publ, 222.

Mkrtchyan N.M. (2016). Pedagogical practice in a system of higher Russian education: history and modernity of philological sciences. Questions of theory and practice. Tambov, 11(65), 194-19.

Obradovich MSc Bosho. (2013). Pedagogical practice, way of connecting pedagogical theory and practice. International journal of cognitive research in science, engineering and education, 1(2).

Pavlova Ya.V. \& Sakovich S.I. (2017). Organization of pedagogical practice in a university. Modern scientific researches and innovations, 3 .

Polyakova T.S. (1983). Analysis of difficulties during pedagogical work of teachers-beginners. Moscow.

Rogov E.I. (1999). Desk book of a practical psychologist. Methods handbook. In 2 pts., 2nd ed., rev. ed. 1st pt. Systems of psychologist's work with children of different ages. Moscow, VLADOS Publ., 384.

Sepehri, Z., \& Sheikhalizadeh, M. (2019). Descriptions and overall safety status of sport fields in schools of Ardabil city, Iran. UCT Journal of Social Sciences and Humanities Research, 7(02), 1-5.

Slastenin V.A. (2018). Psychology and pedagogy in 2 pts. Slastenin V.A., Kashirina V. Eds. 2nd pt. Pedagogy: book for secondary vocational education. Moscow, Yurite Publ, 374.

Ushinskii K.D. (1959). Collected works. Moscow, 10.

Voronov V.K. (2013). Gerashchenko L.A., Cognitive barriers in training students of higher education institutions, Methodology for their elucidation and overcoming. Modern education and computer science, 2, 1-11

Vygotskii L.S. (2019). The History of development of superior mental functions. Moscow. Yurite Publ, 336.

Zhirkova Z.S. (2012). Pedagogical practice of students - preparation for main kinds of professional activity. Fundamental researches, 6-2, 360-364. 